\title{
Reject, Revise, and Resubmit — Please...
}

\author{
Steven J. Cooke \\ Steven J. Cooke (Steven_Cooke@ carleton.ca), Fish Ecology and Conservation Physiology Laboratory, Institute of \\ Environmental Science and Department of Biology, Carleton University, Ottawa, ON, Canada K1S 5B6
}

Seriously-PLEASE! Journals want us to revise and resubmit papers that are rejected because it benefits them in two specific ways. First, it gives the illusion that the journals are highly selective by rejecting material and then accepting it later as a new submission. The rejection rate increases which increases prestige in some twisted way which also seems to attract papers in greater numbers. Indeed, Wardle (2012) notes that journal acceptance rates in ecology and evolution are "plummeting". Could that be an artefact of excessive use of "reject, revise and resubmit"? Second, it skews the statistics for time between submission and both first and final editorial decision. Again, this information is shared with potential authors, often via journal advertising material, thus attracting authors given the apparent rapidity in which one can expect their paper to be handled. I submit that the often used editorial decision to "revise and resubmit" does nothing but feed an already broken system (McCook 2006, Lortie 2013).

It is my assertion that in most cases "revise and resubmit" is simply a dramatic version of "major revisions." "Major revisions" does not imply that a paper will eventually be accepted. As an author, I do not treat a paper that has been given the moniker of "revise and resubmit" any differently than one needing "major revisions." One issue with "revise and resubmit" is that there is often no specific space or mechanism by which to upload and share the list of revisions with potential referees. That is, because it is treated as a new submission, the referees may not have access to the article history, meaning that the efforts taken by authors to document changes are somewhat moot, and time of both authors and referees can be wasted (if, for example, an author rebuts a criticism but the paper is again criticized by the same or a new referee for the same issue). This of course assumes that a paper that is revised and resubmitted actually goes to peer review.

As a co-author, I recently had a paper "rejected with invitation to resubmit" with it being explicitly noted by the editor that it was a "rapid publication journal." What does that mean? Well, in our case, it meant that the revised (new) manuscript was not sent for peer review and was simply accepted 4 days later. On the paper, it clearly shows that the paper was received on December $13^{\text {th }}$ and accepted on December $17^{\text {th }}$. We never received any reviews, nor were required to respond to any science-based editorial queries (we did have to change a figure because photo quality was insufficient). So-I would argue that another statistic that should be tracked is the number of submissions that are accepted without being sent for external peer review. Using the same hokey accounting system of the journal to rack up extra rejections, I would knock them down for papers accepted without peer review. Isn't real peer review by external experts the foundation for our modern peer review system (Rowland 2002)?

As an editor, I use the "revise and resubmit" decision sparingly because I do not wish to play games-and especially because I want to keep all journal correspondence regarding a given submission together in a single, easy-to-access and cross-referenced digital file. Interestingly, "revise and resubmit" is a common selection by referees, perhaps because they are so used to receiving the same decision on their work. I would also submit that the "revise and resubmit" decision is exceedingly confusing to early career researchers (Schäfer et al. 2011). As we try to welcome them into a community based on critical analysis intended to improve scientific research and outputs, why confuse them and make them party to nonsensical games? As an 
author, I have never looked at the total time required for a paper to matriculate through the peer-review system. Instead, I focus on time from initial submission to first editorial decision with peer reviews in hand. That is a TRUE measure (assuming that papers rejected without being sent for review are removed from the accounting) of journal speed and one that is worthy of tracking. And, I would argue that the real driver of speed is editor and journal office persistence. Whenever I see periods of 4 or 5 days as noted above listed as time between submission and acceptance, I shake my head knowing that we have "pleased" the journal and editor in that all too often we do indeed "revise and resubmit" work to the same journal from which it was initially rejected. For the reasons noted above, I submit that this process is confusing and intentionally manipulates publication statistics. Editor and editorial incompetence and malpractice abound (Cooke and Lapointe 2012) and it is time that we hold them accountable for their behaviour.

\section{References}

Cooke, S.J., and N.W.R. Lapointe. 2012. Addressing editor(ial) malpractice in scientific journals. Ideas in Ecology and Evolution 5:84-92. CrossRef

Lortie, C.J. 2012. Hansel and Gretel: The future of publishing wicked witch-free. Ideas in Ecology and Evolution 5: 99-102. CrossRef

McCook, A. 2006. Is peer review broken? The Scientist 20:26.

Rowland, F. 2002. The peer-review process. Learned Publishing 15: 247-258. CrossRef

Schäfer, R.B., Cooke, S.J., Arlinghaus, R., Bonada, N., Brischoux, F., Casper, A.F., et al. 2011. Early career researchers' perspectives on the current and future state of the scientific publication process in ecology. Freshwater Biology 56: 2405-2412. CrossRef

Wardle, D.A. 2012. On plummeting manuscript acceptance rates by the main ecological journals and the progress of ecology. Ideas in Ecology and Evolution 5: 13-15. $\underline{\text { CrossRef }}$ 